\title{
JURISDIÇÃO E PROCESSO: A NECESSÁRIA SUPERAÇÃO DO PROTAGONISMO E DO ATIVISMO JUDICIAL PARA A CONSTRUÇÃO DE UM PROCESSO DEMOCRÁTICO
}

\section{Jurisdiction and Procedure: The most needed improvement from playing a major role and from the judicial activism to the construction of the democratic procedure}

\section{Paola Lorena Pinto dos Santos ${ }^{1}$}

Resumo: O fortalecimento da jurisdição constitucional no Brasil pode ser imputado, ainda que não exclusivamente, à mudança paradigmática proporcionada pela Constituição Federal 1988. Considerando que todo ato jurisdicional pode ser tido como jurisdição constitucional, e que o processo deve servir como meio para prestação da tutela jurisdicional, necessário que ele corresponda à atual fase do constitucionalismo brasileiro. Mas para que esse objetivo seja alcançado, o comportamento solipsista,
Abstract: The strengthening of constitutional jurisdiction, in Brazil, could be attributed to the paradigm change provided by the Federal Constitution of 1988. Considering that every jurisdictional act can be considered as constitutional jurisdiction and that the case should serve to provide jurisdictional tutelage, it needs to match the current phase of the Brazilian constitutionalism. However, in order to achieve this goal, the solipsist behavior, which mainly finds shelter in the judicial activism and

1 Pós-Graduada em Direito Público pela Universidade Regional de Blumenau (FURB). Graduada em Direito pela Universidade do Contestado (UnC). E-mail: paola.Iorena@hotmail.com. 
que encontra guarida no protagonismo e no ativismo judicial no âmbito, principalmente, do processo civil, deve ser considerado obstáculo a ser ultrapassado, já que responsável por aumentar o poder decisório dos juízes que, em muitos casos, decidem "conforme sua consciência", minorando a importância dos elementos que as partes em contraditório podem trazer para produção das decisões jurídicas. Aliado a isso, a coerência e a integridade do Direito devem servir como norteadoras de todas as decisões judiciais, a fim de que não haja o rompimento com a tradição constitucional, principalmente, e os decisionismos não se façam presentes, como corolários do protagonismo e do ativismo judicial.

Palavras-chave: Jurisdição constitucional. Protagonismo judicial. Ativismo judicial. Processo jurisdicional democrático. protagonism of the civil procedure, must be considered an obstacle to overcome. It is responsible for increasing the judges' decision power that, in many cases, decide "according to their conscience," lessening the importance of elements that both parties might bring to the production of legal decisions. Furthermore, the consistency and integrity of the Law should serve as guides to all judgments. Essentially, in order to avoid a disruption with the constitutional traditionand decisions are not going to be present as corollaries of the judicial activism and protagonism.

Keywords: Constitutional jurisdiction. Judicial protagonism. Judicial activism. Democratic and jurisdictional process.

\section{INTRODUÇÃO}

A jurisdição constitucional tem sido objeto de intensas discussões teóricas, em virtude, principalmente, da expansão do Poder Judiciário no cenário nacional atual. Observa-se que, como consequência desta expansão, juízes e tribunais vêm assumindo certo protagonismo em suas decisões, o que nem sempre se configuraria numa atuação constitucionalmente adequada.

Diante disso, propõe-se investigar, dentro da jurisdição constitucional, o protagonismo/ativismo judicial que com frequência tem sido a ela associado, e que pode surgir em face 
da necessidade da prestação da tutela jurisdicional pautada nos direitos fundamentais, por significar demasiada amplitude aos poderes do magistrado, característica própria do atual contexto de supremacia constitucional. Ademais, intenta-se destacar a necessidade de se pensar um processo democrático que possa servir de meio para concretização dos direitos fundamentais sem, no entanto, contribuir para decisões que ultrapassem o poder que o constituinte outorgou ao Judiciário.

Parte-se da hipótese de que em virtude de a prestação jurisdicional dever ocorrer sob o prisma constitucional, visando à realização dos direitos fundamentais no mundo fático, o protagonismo/ativismo judicial que daí surge não representa um comportamento legítimo, mas antes prejudicial ao desenvolvimento de um processo democrático que enseja a participação das partes, além de afrontoso à separação dos poderes. Assim, o processo jurisdicional constitucional é um importante meio para, além de concretizar os direitos fundamentais, apresentar os limites necessários a eventuais protagonismos/ativismos que podem originar decisionismos.

O contexto histórico-político no qual se pretende trabalhar é o da pós-Constituição de 1988 que, diante das intensas modificações, produziram um aumento de demandas submetidas ao Poder Judiciário, levando a sua frequente inserção em temas que pertenciam até então às esferas de decisão dos demais poderes, isto é, Executivo e Legislativo, o que ocasiona também a discussão acerca de sua legitimidade democrática.

Procurar-se-á desenvolver a pesquisa utilizando o método sócio-jurídico, em razão da necessidade de se buscar em outros campos do saber - e não apenas o jurídico - possíveis contribuições para comprovação da hipótese.

\section{A EXPANSÃO DA JURISDIÇÃO CONSTITUCIONAL BRASILEIRA}

É uma tendência contemporânea delegar às Cortes Constitucionais maior poder de decisão em matérias notadamente 
políticas. Mesmo em países cuja tradição é a do Civil Law, ganha destaque cada vez mais a atuação do Poder Judiciário, que passou a ter participação mais efetiva nas decisões de interesse da comunidade, algo até então associado com mais frequência ao sistema do Commom Law (TASSINARI, 2012, p. 19).

Os países europeus que sofreram diretamente as consequências da Segunda Guerra Mundial adotaram gradativamente - a partir da segunda metade do século XX - constituições de caráter social, evidenciadoras de um Estado de Bem-Estar, voltado à concretização dos direitos fundamentais e à promoção da dignidade da pessoa humana. Essa circunstância foi fundamental para que as constituições angariassem o posto de normas jurídicas, não mais admitidas como um documento político.

Diante dessas modificações que se operaram, principalmente no lado ocidental, a jurisdição constitucional ${ }^{2}$ ganhou contornos muito maiores em razão da necessidade de que cada Constituição fosse cumprida, o que, no Brasil, resultou num evidente deslocamento do poder decisório de Executivo e Legislativo para o Judiciário, grande parte em razão da abrangência do texto promulgado, inaugurando a uma nova democracia, após um longo período de exceção. Ainda que as causas de uma "supremacia judicial” ${ }^{3}$ verificada no Brasil sejam diversas daquelas que puderam ser observadas em países como os Estados Unidos, é

2 "A expressão jurisdição constitucional designa a interpretação e aplicação da Constituição por órgãos judiciais. No caso brasileiro, essa competência é exercida por todos os juízes e tribunais, situando-se o Supremo Tribunal Federal no topo do sistema. A jurisdição constitucional compreende duas atuações particulares. A primeira, de aplicação direta da Constituição às situações nela contempladas. [...] A segunda atuação envolve a aplicação indireta da Constituição, que se dá quando o intérprete a utiliza como parâmetro para aferir a validade de uma norma infraconstitucional em meio a diferentes possibilidades (interpretação conforme a Constituição). Em suma: a jurisdição constitucional compreende o poder exercido por juízes e tribunais na aplicação direta da Constituição, no desempenho do controle de constitucionalidade das leis e dos atos do Poder Público em geral e na interpretação do ordenamento infraconstitucional conforme a Constituição." (BARROSO, 2011a, p. 359).

3 Cf. VIEIRA, 2008, p. 441-463. O autor lista algumas das circunstâncias (fáticas e jurídicas) que podem servir de explicação para o acúmulo de poderes pelo Supremo Tribunal Federal nos últimos anos, o que explica o título do artigo, chamado Supremocracia. 
possível perceber que as consequências são, em muito, parecidas: maior entrelaçamento entre o direito e a política, e a incorporação, pelos juízes, de um discurso que vai muito além da mera menção a textos de lei. A Constituição passa a ser o centro do sistema jurídico, e o Poder Judiciário assume o locus de principal articulador entre sociedade e os demais poderes.

Levando em consideração que - como nos adverte Motta ${ }^{4}$ (2010, p. 29) - todo ato judicial é jurisdição constitucional, vemos emergir, a cada dia, a necessidade de que juízes e tribunais façam uma leitura constitucional adequada e se comprometam com a concretização da Constituição. Disso surgem os seguintes dilemas: qual seria o limite para uma jurisdição constitucional democrática? Até que ponto podemos considerar que há na atividade jurisdicional um protagonismo judicial que deve ser combatido? Haveria uma inclinação de juízes e tribunais brasileiros em adotar uma postura ativista? $\bigcirc$ processo, entendido com um direito fundamental, pode servir como principal ferramenta para, além de concretizar direitos fundamentais, limitar a atividade jurisdicional, moldando-a à Constituição? Como é possível pensar a construção de um processo democrático?

Todas essas questões são úteis para nos guiar numa investigação que tem como propósito compreender como o protagonismo judicial (e de uma maneira mais específica, o ativismo judicial) passou a fazer parte do cotidiano de juízes e tribunais brasileiros, principalmente, levando em conta que a tutela jurisdicional constitucional deve ser materializada concretamente a partir dos direitos fundamentais, o que pode implicar num maior protagonismo/ativismo do juiz. Ademais, é necessário entender como o processo civil, visto a partir de um prisma constitucional, pode ser importante meio (sem deixar de ser considerado, ele mesmo, um direito fundamental) para conduzir a uma jurisdição democrática, ou em outras palavras, que seja desem-

4 "Afinal de contas, é como diz Lenio Streck: qualquer ato judicial é de jurisdição constitucional, de modo que é dever do juiz examinar, antes de qualquer outra coisa, a compatibilidade do texto normativo infraconstitucional com a Constituição." (MOTTA, 2010, p. 29). 
penhada de modo a garantir a participação das partes, concretizar os direitos constitucionais sem que, no entanto, precise-se recorrer a decisões ativistas, tendo em vista, portanto, que o ativismo judicial - principalmente - é aqui considerado sob uma perspectiva crítica.

\section{PROTAGONISMO E ATIVISMO JUDICIAL}

O protagonismo judicial - que pode ser compreendido num sentido amplo - é apontado por Motta (2010, p. 41) como um legado deixado pelo positivismo, já que os "positivismos jurídicos" foram responsáveis pelo afastamento das questões concretas da sociedade do discurso jurídico, isto é, diante da impossibilidade de que todos os embates sociais fossem previstos em regras jurídicas, houve a aceitação por parte dos positivistas de deixar ao arbítrio judicial a decisão acerca daqueles casos não contemplados. Nas palavras do autor "[...] a matriz positivista sequestrou o mundo prático”. (MOTTA, 2010, p. 34).

O ativismo judicial, por sua vez, está relacionado a um país e a um contexto determinado - os Estados Unidos - e, a princípio, pode ser compreendido como uma nova roupagem do protagonismo judicial ou no mínimo uma subespécie sua (ao menos no Brasil).

As discussões em torno do ativismo judicial - e propriamente o seu nascimento - tiveram início em 1803, nos Estados Unidos da América, no caso Marbury versus Madison, no qual se discutia a possibilidade de William Marbury tomar posse como juiz de paz diante da nomeação realizada pelo presidente John Adams às vésperas de deixar o cargo. O então Chief Justice da Suprema Corte norte-americana, John Marshall ${ }^{5}$, declarou a

5 Posner, que considera John Marshall um pragmatista, afirma que, embora este não possa ser considerado um "intelectual de verdade", em razão da ausência de uma cultura ampla e de personalidade especulativa, foi fundamental não só para manter a unidade da nação que, naquele momento (início do século XIX), corria riscos de se dissolver, mas também para o desenvolvimento de uma jurisprudência mais adequada ao contexto social e menos voltada a um continuísmo dos princípios do formalismo legal. Cf. POSNER, 2010, p. 66-72. 
inconstitucionalidade da seção 13 do Judiciary Act (que previa a competência da Corte para o julgamento) afirmando, naquela ocasião, que o caso proposto por Marbury em face de James Madison (secretário do presidente eleito Jefferson, e responsável por efetivar a investidura) não poderia ser julgado por se tratar de afronta à Constituição, já que esta não teria conferido tal poder à Corte. A partir dessa decisão, tem início o controle de constitucionalidade norte-americano (judicial review) (TASSINARI, 2012, p. 23).

Segundo Tassinari (2012, p. 25), diferentemente dos Estados Unidos, em que a discussão sobre o ativismo judicial tem cerca de 200 anos de história, no Brasil um pretenso ativismo só foi realmente possível (ou perceptível) após a promulgação da Constituição de 1988 que, ademais, foi responsável pela redemocratização do país e pela expansão da previsão de direitos, o que possibilitou o aumento considerável no número de demandas, ensejando também a discussão dos temas colocados em pauta. De modo geral, o constitucionalismo democrático que decorreu da Constituição foi a fonte na qual o Judiciário encontrou guarida para uma postura ativista (TASSINARI, 2012, p. 26).

Diante desses apontamentos, pode-se dizer que a perspectiva na qual Tassinari (2012) trabalha é crítica: o ativismo judicial desenvolvido no Brasil não apresenta - como não poderia deixar de ser - as mesmas características daquele desenvolvido nos Estados Unidos, em razão de que há uma diferença substancial com relação ao contexto histórico e jurídico no qual emergiu. Por conta disso, uma má compreensão, ou recepção irrefletida pela doutrina brasileira do ativismo judicial norte-americano, acaba por dificultar a estruturação de uma teoria judicial eminentemente brasileira ${ }^{6}$.

6 "Em outras palavras, no Brasil, poucos têm sido os esforços voltados para elaborar um quadro com sustentabilidade teórica que dê conta de compor todos os matizes necessários para consolidar uma teoria judicial que esteja adequada ao Estado Democrático de Direito, com todos os seus indispensáveis desdobramentos."

(TASSINARI, 2012, p. 20) 
Nunes e Bahia (2009) atentam para a existência, cada vez mais crescente, de um discurso proveniente de parte da doutrina e do Judiciário em defesa de um ativismo judicial relacionado à análise, pelos magistrados, dos impactos políticos, econômicos e sociais de suas decisões. De acordo com eles, essa postura não só é, em termos fáticos, diante da nossa atual estrutura, impossível de ser alcançada, como atentatória, pois estaria colocando em segundo plano a qualidade das decisões e a função principal do juiz que é a de julgar.

Luís Roberto Barroso (2013) surge, a princípio, como principal entusiasta do ativismo judicial no Brasil'. Para o Ministro do Supremo Tribunal Federal, a expansão do Poder Judiciário é um fenômeno mundial, e necessário para a manutenção das regras do jogo democrático. O ativismo judicial despontaria, assim, como uma atitude proativa de ampliação do sentido e do alcance dos direitos constitucionais pelo Judiciário, principalmente quando outros setores, responsáveis por efetivá-los, se omitirem (BARROSO, 2011b, p. 279).

Antes de concluir este tópico, faz-se necessária uma última observação. $\mathrm{O}$ ativismo judicial não pode ser confundido com a judicialização da política. Isso porque, como bem demonstrou Werneck Vianna (1999), a judicialização da política e das relações sociais no Brasil ocorreu após a Constituição Federal de 1988 ter disponibilizado um extenso rol de direitos (em especial, os fundamentais), de mecanismos para sua reivindicação, além de um número considerável de legitimados, notadamente, para a impetração de ADI (ação direta de inconstitucionalidade). Por consequência, um número elevado de questões passou a ser submetidas ao Supremo Tribunal Federal, sendo elas objeto de interferência da Corte, algo até então inédito. Assim, de acordo com Tassinari (2012, p. 36-37), enquanto a judicialização

7 Não obstante tenha afirmado, em entrevista recente "que não há um surto ativismo judicial no Brasil." (Cf. BARROSO, Luís Roberto. Tribunal não cumpre seu papel com 80 mil processos. Disponível em: <http://www.conjur.com.br/2013-jun-07/entrevista-luis-roberto-barroso-ministro-supremo-tribunal-federal>. Acesso em: 14.03.2015). 
da política é um fenômeno contingencial, o ativismo traduz a posição do Poder Judiciário de ir além dos limites constitucionais. Portanto, embora correlacionados, tratam-se de fenômenos diversos.

\section{TUTELA JURISDICIONAL E PROCESSO}

A tutela jurisdicional pode ser compreendida como a efetiva realização dos direitos fundamentais no âmbito fático, isto é, não se trata de mera resposta ao pedido formulado pelos litigantes, mas se liga à preocupação de solucionar os problemas colocados, partindo-se da normativa constitucional (RODRIGUES; LAMY, 2012, p. 60).

Para Motta (2010, p. 200) o processo é um direito constitucional aplicado. Lamy e Rodrigues (2012, p. 126), por seu turno, destacam a importância de o processo ser visto a partir da uma perspectiva constitucional, enfatizando a sua importância como instrumento concretizador efetivo de direitos na realidade das partes. Nas palavras desses autores:

[...] o processo contemporâneo é o instrumento de que serve o Estado para, tanto no exercício da sua função jurisdicional quanto fora dela, com a participação das partes e obedecendo ao procedimento estabelecido na legislação específica, eliminar os conflitos de interesses, solucionando-os; um ato jurídico complexo constituído pela operação de um núcleo de direitos fundamentais sobre uma base procedimental, não somente no âmbito da jurisdição e não apenas para declarar os direitos, mas principalmente para satisfazê-los no mundo dos fatos, na vida dos litigantes ${ }^{8}$.

É importante ter-se em mente que a referência ao processo como "instrumento" não é no sentido de estabelecê-lo como mera técnica, destituída de conteúdo, de que dispõe o juiz para ser utilizado como the parecer conveniente, mas antes que se constitui em um direito fundamental, dotado de uma

8 Grifo dos autores. 
instrumentalidade essencial à concretização da Constituição e à proteção dos direitos dos jurisdicionados contra eventuais ingerências estatais, diante, principalmente, do protagonismo do juiz. Nas palavras de Motta (2010, p. 22), “o 'processo' é (bem) mais do que um 'instrumento' do juiz e da 'jurisdição', ao menos enquanto esta for compreendida como a tarefa de o juiz dizer (aquilo que entende d)o Direito”. Já Dierle Nunes (2012, p. 41, nota 5) reconhece a importância da instrumentalidade técnica do processo, afirmando, no entanto, que:

A instrumentalidade técnica não deve ser confundida com as defesas de linhas instrumentalistas, do realismo norte-americano ${ }^{9}$, ou brasileiras, que acreditam no protagonismo judicial como mecanismo para aplicação do direito com base em valores uniformemente compartilhados pela sociedade, eis que se acredita na existência desses valores uniformes em sociedades altamente complexas e plurais como as nossas.

Não se compartilha da ideia das teorias instrumentalistas, fortalecidas que foram no direito processual brasileiro - principalmente pelas reformas processuais, que repristinam teorias ultrapassadas como a do "socialismo processual" (STRECK, 2010 , p. 105) -, já que apostam no juiz como agente concretizador da "justiça social", levando inevitavelmente ao fortalecimento do protagonismo do juiz.

Nesse sentido, Motta (2010, p. 66-69) lembra que o perfil da legislação referente ao processo possui traços de um "liberalismo processual", o que a identifica com um modelo de Direito praticado sob os auspícios de um Estado Liberal, no

9 O Realismo Jurídico, corrente teórica que nasceu no início do século $X X$, teve como seus expoentes mais notáveis Roscoe Pound, Benjamin Cardozo e Oliver Wendell Holmes. Este último, juiz da Suprema Corte norte-americana de 1902 a 1932, é a quem se reputa o pioneirismo na proposição do estudo entre direito e economia. Cf. POGREBINSCHI, Thamy. O que é pragmatismo jurídico? Disponível em: <http://www.cis.puc-rio.br/cedes/PDF/paginateoria/pragmatismo.pdf>. GODOY, Arnaldo Sampaio de Moraes. O Realismo Jurídico em Oliver Wendell Holmes Jr. Disponível em: <http://www.arnaldogodoy.adv.br/artigos/holmes.htm>. Acesso em: 14.03.2015. 
qual impera a autonomia privada e o cidadão é apenas "parte" na relação processual, cuja principal "tarefa" está em se sujeitar às regras pré-estabelecidas. $\mathrm{O}$ juiz, por seu turno, tem tão só a incumbência de decidir, de modo imparcial, a partir daquilo que é trazido pelas partes. Por outro lado, desponta também no processo um viés típico do Estado Social, em que o juiz assume uma postura "paternalista" diante dos pedidos realizados pelos jurisdicionados, que passam, justamente, a ocupar um lugar passivo, sem efetiva participação no processo. Nesse último aspecto, "socializador", é que se encontraria o protagonismo judicial. Tais traços - que denotam duas faces de certo modo antagônicas - afastariam o processo do modelo então demandado pelo Estado Democrático de Direito, no qual estamos sob a égide desde a Constituição de 1988.

Dessa forma, surge a necessidade de enxergar o processo dentro do atual contexto constitucional no qual se insere, regido ainda por um Estado Democrático de Direito, o que se faz necessário garantindo os direitos fundamentais, sem que se caia num liberalismo processual (no qual as partes são dominantes no processo) e muito menos num socialismo processual, que ensejaria demasiada participação do juiz. Assim, é preciso partir-se em busca de um devido processo legal capaz de proporcionar ao juiz mecanismos de concretização dos direitos fundamentais, garantindo a tutela jurisdicional, mas sem que necessite recorrer a protagonismos/ativismos ou mesmo obstar o papel das partes na relação processual, nos casos em que essa se faz necessária.

\section{A CONSTRUÇÃO DE UM PROCESSO DEMOCRÁTICO A PARTIR DA SUPERAÇÃO DO PROTAGONISMO E DO ATIVISMO DO JUIZ}

Como já se falou à saciedade, a jurisdição constitucional atual desfruta de um momento único, em virtude do destaque que o Poder Judiciário angariou após a Constituição Federal de 1988. É notório também que a tutela jurisdicional deve ser pres- 
tada com vistas a concretizar os direitos fundamentais, o que implica reconhecer o processo como um direito fundamental em si mesmo, e apto a tal propósito.

Contudo, nota-se que direito processual civil ainda se apresenta muito dependente do protagonismo do juiz, como se ele representasse a única alternativa (ou ao menos a mais razoável) para solucionar todo o caos em que o Judiciário atualmente se encontra. Não se mostra legítimo que a jurisdição seja prestada de acordo com a conveniência do magistrado, já que isso pode significar decisões diferentes para casos idênticos. Ademais, a Constituição dispõe de uma base normativa muito rica, o que por si só já demonstra a desnecessidade de decisões descoladas da sua principiologia.

$\mathrm{Na}$ tentativa de se desvencilhar do positivismo jurídico, o protagonismo judicial acaba sendo frequentemente revigorado (assim como o ativismo judicial) a partir da defesa, por exemplo, da instrumentalidade do processo, do livre convencimento do juiz e da livre apreciação da prova (todos estes considerados "princípios"10). Ocorre que estes princípios estão diretamente ligados à crença de que o juiz possui capacidade de "encontrar" a solução para cada caso ${ }^{11}$ influenciado pelos valores da sociedade na qual vive, numa evidente busca pela "justiça social”. Como se fosse possível, diante da pluralidade e complexidade social na qual estamos imersos, definir o que seja justiça social, e, a partir disso confiar na sapiência do juiz para destacar os valores supremos da sociedade que poderiam influenciá-lo nas decisões.

Conforme destaca Dierle Nunes (2013), a construção de um processualismo democrático possui como um dos seus pilares

10 Para uma crítica ao que Streck chama de pamprincipiologismo: Cf. STRECK, Lenio Luiz. O pamprincipiologismo e a flambagem do Direito. Revista Consultor Jurídico, 10 de outubro de 2013. Disponível em: <http://www.conjur.com.br/2013-out-10/senso-incomum-pamprincipiologismo-flambagem-direito>. Acesso em: 14.03.2015.

11 Alerta Lenio Streck que em face da atual tendência de commonlização do Direito, não se julgam causas, mas teses. Cf. STRECK, Lenio Luiz. Juiz não é gestor nem gerente. Ele deve julgar. E bem! Revista Consultor Jurídico, 8 de agosto de 2013. Disponível em: <http://www.conjur.com.br/2013-ago-08/senso-incomum-juiz-nao-gestor-nem-gerente-juiz-julgar-bem>. Acesso em: 14.03.2015. 
a "necessidade de adoção do contraditório como garantia de influência e não surpresa na formação das decisões" ${ }^{12}$ Isso significa garantir maior participação das partes no processo, regidas pelo contraditório, para que o juiz possua subsídios - democraticamente discutidos - para a construção de suas decisões. Não que isso implique atrelamento do juiz apenas aos argumentos exarados, mas se trata de tentar evitar o afastamento radical do magistrado das questões trazidas pelos litigantes, para que a sentença - eminentemente - não se constitua num elemento de surpresa para eles. Se o magistrado estiver, por exemplo, a serviço apenas de sua consciência (STRECK, 2010), algo que, lamentavelmente, ainda é muito comum no Direito brasileiro, certamente que não há nenhuma garantia de que ele respeitará os limites mínimos de discussão formados durante o processo. Todos devem assumir as suas responsabilidades, sejam partes ou não, estejam dentro ou fora do processo. É preciso fugir de uma concepção protagonista em prol da defesa da comparticipação entre todos os atores jurídicos envolvidos (NUNES; BAHIA, 2008).

Lenio Streck (2013), que trabalha com a visão dworkiniana de coerência e integridade do Direito, ressalta a importância de se privilegiar não apenas a estabilidade das decisões, mas também a sua coerência, no sentido de que a aplicação isonômica dos princípios deve ocorrer quando se tratarem de casos idênticos, e a integridade, que deve restar assegurada pela força normativa da Constituição, por representar verdadeira blindagem contra arbitrariedades interpretativas ${ }^{13}$.

12 NUNES, Dierle José Coelho. Novo CPC consagra concepção dinâmica do contraditório. Revista Consultor Jurídico, 8 de outubro de 2013. Disponível em: <http:// www.conjur.com.br/2013-out-08/dierle-nunes-cpc-consagra-concepcao-dinamica-contraditorio>. Acesso em: 14.03.2015.

13 "A coerência assegura a igualdade, isto é, que os diversos casos terão a igual consideração por parte dos juízes. Isso somente pode ser alcançado através de um holismo interpretativo, constituído a partir do círculo hermenêutico. Já a integridade é duplamente composta, conforme Dworkin: um princípio legislativo, que pede aos legisladores que tentem tornar o conjunto de leis moralmente coerente, e um princípio jurisdicional, que demanda que a lei, tanto quanto o possível, seja vista como coerente nesse sentido. A integridade exige que os juízes construam seus argumentos de forma integrada ao conjunto do direito. Trata-se de uma garantia 
É preciso deixar claro que um processo democrático só pode ser construído com o abandono do solipsismo judicial, tão bem criticado por Streck (2010) ${ }^{14}$, e que está diretamente ligado ao apego demasiado à filosofia da consciência, que se sustenta na ideia de essencialidades, dando ao juiz o lugar de sujeito capaz de desvelar a essência dos objetos. Como se o sentido da "norma" fosse algo inerente a ela mesma, e nos coubesse descobri-lo. Pensar assim é esquecer que a norma se dá no caso concreto, pois antes disso, o que existe é apenas seu texto (STRECK. 2009, p. 159-171).

Não parece admissível no atual estágio do Direito, regido por uma Constituição Democrática, que a pretexto de concretizar os direitos fundamentais, preste-se a tutela jurisdicional distante dos próprios limites apresentados pela Constituição, tendo em vista que ela denota muito bem a necessidade de respeito ao contraditório e à ampla defesa (art. 5º, inciso LV), além da obrigatoriedade de fundamentação de todas as decisões (art. 92, IX, da CF/88).

Mais que isso, o processo não pode servir apenas como um instrumento da jurisdição, manejável ao sabor das convencionalidades, mas deve ser tido como um direito fundamental das partes, e isso leva ao seu pleno direito de comparticipação, além de terem a garantia de que o juiz julgará com respeito à coerência e à integridade do Direito, atendo-se ao que foi produzido conforme a tradição constitucional.

contra arbitrariedades interpretativas. A integridade limita a ação dos juízes; mais do que isso, coloca efetivos freios, através dessas comunidades de princípios, às atitudes solipsistas-voluntaristas. A integridade é uma forma de virtude política. A integridade significa rechaçar a tentação da arbitrariedade." (STRECK, Lenio Luiz. Por que agora dá para apostar no projeto do novo CPC! Revista Consultor Jurídico, 21 de outubro de 2013. Disponível em: <http://www.conjur.com.br/2013-out-21/lenio-streck-agora-apostar-projeto-cpc>. Acesso em: 14.03.2015).

14 "Despiciendo, nesta altura, lembrar que, quando critico o 'solipsismo judicial' ou, o que é a mesma coisa, as 'decisões conforme a consciência do julgador', tenho em mente a tese de que as decisões judiciais não devem ser tomadas a partir de critérios pessoais, isto é, a partir da consciência psicologista. Insisto, pois, que se trata de uma questão relacionada à superação do paradigma daquilo que se denomina de 'filosofia da consciência'." (STRECK, 2010, p. 106.). 
A construção de um processo civil democrático passa, portanto, pelo abandono do protagonismo e do ativismo do juiz, mesmo porque um solipsismo desse jaez está intrinsicamente ligado ao positivismo jurídico o que, em tempos de Constitucionalismo Contemporâneo ${ }^{15}$, não se mostra adequado. Acrescente-se a isso, a importância de se resgatar o papel da doutrina, já que o Direito não é aquilo que juízes e Tribunais dizem que é, como comumente se pensa (STRECK, 2010, p. 107). Em síntese: a prestação da tutela jurisdicional não pode ficar à mercê da vontade do julgador.

\section{CONCLUSÃO}

Viu-se operar no Direito brasileiro uma modificação paradigmática com a promulgação da Constituição Federal de 1988 que, ainda que não tenha atingido um patamar razoável de efetividade, proporcionou o fortalecimento da jurisdição constitucional a partir da abertura proporcionada para a análise de temas até então distanciados do Poder Judiciário. Contudo, esta ampliação trouxe como uma de suas consequências o aumento do poder de decisão dos juízes. $\mathrm{O}$ protagonismo judicial que já podia ser percebido em virtude da adoção de um Código de Processo Civil (Lei no 5.869/1973) com traços, ao mesmo tempo, de um lado de liberalismo processual e de outro de um socialismo processual, foi fortalecido pela adoção de posturas ativistas no trato dos direitos fundamentais, eminentemente, a partir da colonização do pensamento jurídico norte-americano, o que por si só já demonstra um déficit de legitimidade, tendo em vista a ausência de reflexão sobre o contexto de criação e desenvolvimento do ativismo judicial.

O senso comum teórico dos juristas ainda se atém à crença da vontade da lei, de um sentido pré-existente e que poderia ser extraído de seu texto. Não há como sustentar que a tutela

15 A expressão é utilizada por Lenio Streck. Cf. STRECK, 2011, p. 9, nota 2. Disponível em: <http://www.abdconst.com.br/revista5/Streck.pdf>. Acesso em 14.03.2015. 
jurisdicional, para que possa atingir os seus objetivos, deva estar atrelada a uma postura ativa do Poder Judiciário, no qual juízes decidem movidos por sua vontade, a ponto de, até mesmo, invadir a esfera de atuação de outros poderes.

O processo, dentro de uma perspectiva democrática, tal qual como a que se instalou depois de 1988, configura-se como meio para a efetivação dos direitos fundamentais, mas que deve se mostrar apto a garantir a sua realização dentro dos limites traçados pelo constituinte, com respeito à participação dos litigantes na relação jurídica processual, e também dos demais atores jurídicos, naquilo que lhes couber. Sem esquecer que as decisões judiciais devem ser fundamentadas, tendo como base os elementos amplamente discutidos em contraditório pelas partes, respeitando ainda a integridade e coerência do Direito, para que possam ser consideradas constitucionalmente adequadas.

Para que tais intentos constitucionais sejam realizados, um processo democrático se mostra necessário, mesmo porque já ultrapassada a fase liberal e, embora estejamos muito atrelados ao socialismo processual, como bem demonstra a defesa de posturas instrumentalistas, nos encontramos diante do Constitucionalismo Contemporâneo o que por si já é motivo para clamarmos por um processo que dê conta de toda a complexidade jurídica e social.

Por fim, ainda que a resistência à atuação jurisdicional abrangente possa parecer contraditória, em vista da necessidade de efetividade constitucional cada vez mais premente, a escolha democrática feita pelo constituinte implica, necessariamente, na adoção de comportamentos condizentes com ela, ou seja, há um preço a se pagar pela opção adotada. E o preço, neste caso, é conferir aos juízes limites à sua atuação. 


\section{REFERÊNCIAS}

BARROSO, Luís Roberto. O controle de constitucionalidade no Direito brasileiro: exposição sistemática da doutrina e análise crítica da jurisprudência. 5. ed. rev. e atual. São Paulo: Saraiva, 2011a.

. Judicialização, Ativismo Judicial e Legitimidade Democrática. In: COUTINHO, Jacinto Nelson de Miranda; FRAGALE FILHO, Roberto; LOBÃO, Ronaldo (Orgs.). Constituição e ativismo judicial: limites e possibilidades da norma constitucional e da decisão judicial. Rio de Janeiro: Lumen Juris, 2011b.

. Tribunal não cumpre seu papel com 80 mil processos. Revista Consultor Jurídico. Disponível em: <http://www.conjur.com.br/2013-jun-07/ entrevista-luis-roberto-barroso-ministro-supremo-tribunal-federal $>$. Acesso em: 14.03.2015.

GODOY, Arnaldo Sampaio de Moraes. O Realismo Jurídico em Oliver Wendell Holmes Jr. Disponível em: <http://www.arnaldogodoy.adv.br/ artigos/holmes.htm>. Acesso em: 14.03.2015.

LAMY, Eduardo de Avelar; RODRIGUES, Horácio Wanderlei. Teoria Geral do Processo. 3. ed. rev. e atual. - Rio de Janeiro: Elsevier, 2012.

MOTTA, Francisco José Borges. Levando o Direito à Sério: uma crítica hermenêutica ao protagonismo judicial. Florianópolis: Conceito Editorial, 2010.

NUNES, Dierle José Coelho. Processo Jurisdicional Democrático: uma análise crítica das reformas processuais. 1. ed. (2008), 4. reimpr. Curitiba: Juruá, 2012.

. Novo CPC consagra concepção dinâmica do contraditório. Revista Consultor Jurídico, 8 de outubro de 2013. Disponível em: <http://www. conjur.com.br/2013-out-08/dierle-nunes-cpc-consagra-concepcao-dinamicacontraditorio>. Acesso em: 14.03.2015.

NUNES, Dierle José Coelho; BAHIA, Alexandre Gustavo Melo Franco. Ativismo e protagonismo judicial em xeque. Argumentos pragmáticos. Jus Navigandi, Teresina, ano 14, n. 2106, 7 abr. 2009. Disponível em: <http:// jus.com.br/revista/texto/12587>. Acesso em: 14.03.2015.

. Por um novo paradigma processual. Revista da Faculdade de Direito do Sul de Minas, Pouso Alegre, 26: 79-98, jan./jun. 2008. 
POGREBINSCHI, Thamy. O que é pragmatismo jurídico? Disponível em: 〈http://www.cis.puc-rio.br/cedes/PDF/paginateoria/pragmatismo.pdf〉. Acesso em: 14.03.2015.

POSNER, Richard A. Direito, Pragmatismo e Democracia. Trad. Teresa Dias Carneiro; rev. técnica Francisco Bilac M. Pinto Filho. Rio de Janeiro: Forense, 2010.

STRECK, Lenio Luiz. O que é isto - decido conforme a minha consciência? Porto Alegre: Livraria do advogado, 2010.

- Verdade e Consenso. Constituição, Hermenêutica e Teorias

Discursivas da possibilidade à necessidade de respostas corretas em Direito. 3a ed. rev., ampl. e com posfácio. Rio de Janeiro: Lumen Juris, 2009.

. Juiz não é gestor nem gerente. Ele deve julgar. E bem! Revista Consultor Jurídico, 8 de agosto de 2013. Disponível em: <http://www.conjur. com.br/2013-ago-08/senso-incomum-juiz-nao-gestor-nem-gerente-juizjulgar-bem>. Acesso em: 14.03.2015.

. Por que agora dá para apostar no projeto do novo CPC! Revista Consultor Jurídico, 21 de outubro de 2013. Disponível em: <http://www. conjur.com.br/2013-out-21/lenio-streck-agora-apostar-projeto-cpc $>$. Acesso em: 14.03.2015.

. O pamprincipiologismo e a flambagem do Direito. Revista Consultor Jurídico, 10 de outubro de 2013. Disponível em: <http://www. conjur.com.br/2013-out-10/senso-incomum-pamprincipiologismoflambagem-direito>. Acesso em: 14.03.2015.

. Contra o Neoconstitucionalismo. Constituição, Economia e Desenvolvimento: Revista da Academia Brasileira de Direito Constitucional. Curitiba, 2011, n. 4, Jan-Jun. p. 9-27. Disponível em: <http://www. abdconst.com.br/revista5/Streck.pdf>. Acesso em 14.03.2015.

TASSINARI, Clarissa. Jurisdição e Ativismo Judicial: limites da atuação do Judiciário. Porto Alegre: Livraria do Advogado Editora, 2012.

VIANNA, Luiz Werneck et al. A judicialização da política e das relações sociais no Brasil. Rio de Janeiro: Revan, 1999.

VIEIRA, Oscar Vilhena. Supremocracia. Revista Direito GV, dez. 2008, vol. 4, n. 2, p. 441-463.

Artigo recebido em 19/05/2015

Artigo aprovado em 28/08/2015 